DIGITALCOMMONS @WAYNESTATE -
Michigan Journal of Counseling: Research, Theory and Practice

Volume 35 | Issue 1

Article 3

$8-1-2008$

\title{
An Arena for Success: Exploring Equine-Assisted Psychotherapy
}

Sandra L. Kakacek

Northern Illinois University, empires@sbcglobal.net

Allen J. Ottens

Northern Illinois University, aottens@niu.edu

Follow this and additional works at: https://digitalcommons.wayne.edu/mijoc

\section{Recommended Citation}

Kakacek, S. L., \& Ottens, A. J. (2008). An Arena for Success: Exploring Equine-Assisted Psychotherapy, Michigan Journal of Counseling, 35(1), 14-23. doi:10.22237/mijoc/1217548920

This Article is brought to you for free and open access by the Open Access Journals at DigitalCommons@WayneState. It has been accepted for inclusion in Michigan Journal of Counseling: Research, Theory and Practice by an authorized editor of DigitalCommons@WayneState. 


\section{Exploring Equine-Assisted Psychotherapy}

An Arena for Success:

Sandra LKakacek,MS,Ed. and

Allen J. Ottens, Ph.D.

\section{Northern Illinois University}

Contact the authors at: aottens@niu.edu empires@sbcglobal.net

Equine-Assisted Psychotherapy (EAP) is a relatively new experientially-based therapy thathas been applied toindividuals, couples, families, and groups. There is a small but growing literature base that speaks to EAP's potential for working with very challenging clients. Adjudicated juveniles diagnosed with Oppositional Defiant Disorder (ODD) are one such group. This paper contains a brief presentation of a case study that illustrates how EAP can be implemented, a description of the evolution of EAP, the components of EAP, and a discussion of the hypothesized mechanisms that account for its effectiveness.

Key words: Equine Therapy, oppositional clients, EAP Theory, therapeutic factors 
depression and had difficulty controlling his anger. The client was not medicated. He had no known allergies or other medical problems at the time of treatment. He smoked cigarettes and was a substance abuser, with marijuana as his drug of choice. He attended an alternative school that met his needs both academically and emotionally.

He was adjudicated for a violent offense approximately one year prior to being referred for EAP. He had been involved in "talk" therapy for substance abuse and anger management, but with little positive effect. He continued to violate probation due to failing drug screenings and acting-out aggressively. Howard entered therapy without any horse knowledge (which is to be expected) and presented with a great deal of hostility as well as hopelessness.

On his first exposure to EAP, Howard entered the arena and found himself alone among four horses. Much to Howard's surprise, the horses spontaneously circled around him. Without prompting, he began to touch one he dubbed the "Leader" because "he doesn't take no s--- from anyone." When one of the treatment team members asked, "What do you want to share with us today?” Howard announced that he had a drug screening the previous day and boasted that his "drop was clean.” The horses instantly bolted away from him. The client immediately stated, "Wow, they are better than a screening. They knew I failed the test!"

The power of the client's perceptions regarding the incident changed his behavior dramatically. Even though the horses, of course, did not know the results of the "drop," Howard's interpretation of their bolting behavior as having caught him in a lie represented a turning point in his therapy: he had always been capable of manipulating his previous counselors, but now his own metaphoric interpretation of the horses' behavioral reaction was able to display his tendencies to deceive others and himself. Howard often used "Leader" in the course of his therapy. As treatment progressed, Howard entered the arena, asked for a brush, and would literally brush away the stress of the day.

Initially Howard was unable to express emotions other than anger. During an early problem-solving activity, he was instructed to build a course with obstacles, which he did using cones, barrels, and poles, and to move the horse through it. He was also instructed to give names or labels to the obstacles as the things that get in his way of success. Standing and surveying the obstacles in the arena, this adolescent who was so removed from his emotions, identified them as feelings-anger, jealousy, and sadness - that were predominant in his life.

Howard chose Leader and, without touching the horse, was able to guide Leader through the obstacles. He noted the feelings or obstacles where Leader stopped at or had difficulty getting around (i.e. walking around barrels or kicking over the cones). The treatment team utilized these responses to further Howard's awareness of emotional development. For example, the team asked "how do you get around or over your anger?" This metaphoric representation of the horse's emotional responses as compared to Howard's served as a new paradigm for self-growth and change.

Later sessions with problem-solving activities were more complicated. Howard was instructed to build another obstacle course. The treatment team added a twist by strategically placing "temptations"-small piles of hay and grain -in the arena. Howard labeled these as cigarettes, marijuana, and peer pressure- the temptations that Howard readily admitted got him into trouble. The client's goal was to take a horse through the obstacle course. Howard discovered which temptations continued to create problems for him and which were analogous to the treats which tempted the horse. Howard was able to verbalize when he felt tempted by peers and substances. Additionally, Howard was then able to label feelings with each temptation.

Howard continued in treatment and eventually a member of the family was added. Family EAP was replete with the family's understanding of prior miscommunications and what was needed for relational improvement. Session activities revolved around Howard instructing his mother how to approach, catch and halter, and lead a horse. Howard explained to his mother what the equine needed from her as to allow successful catching, and when queried by the treatment team, Howard added what he himself needed from his mother to succeed.

Howard completed twelve sessions. There was documented passing of drug screenings during EAP, resulting in a reduction of recidivism. He has remained out of the court system and has forged a stronger bond with his family.

The creative implementation of EAP in the above case study can best be described with understanding how horses became to be incorporated in counseling. A brief overview of animal-assisted therapy lays the foundation for the development of EAP.

Michigan Journal of Counseling • 35:1 • August 2008 


\section{The Evolution of EAP}

The earliest written anecdotes referring to animalassisted therapy (AAT) date back to 1699 (Parshall, 2003). However, Egyptians, Greeks, Romans, and other ancients were known to make therapeutic use of animals (Pitts, 2005; Kruger, Trachtenberg, \& Serpell, 2004). Usually the physicians of antiquity prescribed patient interaction with dogs, rodents, birds, and fish for their capacity to provide relaxing or kinesthetically soothing experiences (Morrison, 2007). Animals have long been ascribed to providing meaningful relationships with human beings (Morrison). Historical research indicates that ancient Greek and Roman civilizations used animals for treatment of people exhibiting anxiety and depression (Pitts; Kruger, et al.). Utilizing animals for the purposes of mental health treatment interventions was first documented in England in 1699. Dogs ands cats were employed as relaxation techniques for the mentally ill (Parshall).

In the United States, the first medically sanctioned use of dogs and cats as therapeutic agents occurred in the 1940s at an Army convalescent hospital (Parshall, 2003). Patients were exposed to animals as part of the recovery process and reportedly displayed reduced anxiety (Morrison, 2007; Parshall,2003). Parshall theorized research on animal therapy became prominent in 1962 when Levinson, a psychologist, wrote about his dog, Jingles, who accidentally entered the counseling room during a session with an autistic child, who exhibited little to no socialization skills. Reportedly, the child began to interact verbally with the dog. Studies state the results created the beginning of research on using animals in counseling (Vidrine, Owen-Smith, \& Faulkner, 2002). Purdue University and University of Pennsylvania began studying animals assisting in therapy in the 1970’s (Morrison; Parshall).

Animal-Assisted Therapy (AAT) has progressed from a therapeutic novelty to a legitimate treatment intervention that is beginning to establish its effectiveness with medical problems and psychological disorders. Moreover, the species of animals used for therapeutic means has progressed from small, common household pets to include interactions with large, unwieldy animals such as dolphins and horses.

It is only relatively recently that counselors from both the mental health and allied health professions have begun incorporating horses into treatment regimes. The uniqueness of horses' characteristics is one of the reasons equines are becoming a new treatment modality. The sheer size and power of equines often act as the magnet that initially draws people to them; yet, despite horses' size and power, one can establish in their presence a sense of being centered (i.e., feeling relaxed, confident, and connected) (Levinson, 2006). In a sort of paradox, horses, which for centuries provided individuals with the means for external travel, have now emerged as a powerful resource for helping persons make crucial internal journeys as well (McCormick \& McCormick, 1997). One mode for incorporating horses into therapy, which is represented by a number of different therapeutic factions, relies mainly on interventions involving hands-on, physical interactions with horses such as riding, grooming, and balancing activities. This mode is described immediately below. Equine-Assisted Psychotherapy (EAP), which is the focus of this paper, claims that its advantage derives from the therapeutic interpretations of experiential activities between client and horse in which activities are all conducted with no riding.

\section{Equine Therapies Involving Physical Interactions with the Horse}

Equine effects on physical health became prominent in our society with the formation of The North American Riding for the Handicapped Association (NARHA) in 1969. NARHA was established in 1969 with an aim toward promoting its Equine-Facilitated Therapy (EFT) for persons with disabilities. One of EFT's treatment tools, termed hippotherapy (derived from hippos, the Greek word for horse), is used to treat patients of all ages who have neurological, musculoskeletal, or developmental disorders such as cerebral palsy, multiple sclerosis, traumatic brain injuries, autism, and learning or language disabilities (Glasow, 2006). To allow for maximum proprioceptive input, the patient is placed atop the horse, using stirrups but no saddle (DeGuitis, 2003). Patients are accompanied by at least three adults, two sidewalkers, one of whom is a physical, speech, or occupational therapist, and one who leads the horse.

A second treatment tool within EFT is equinefacilitated psychotherapy (EFP). Used by NARHA members EFP relies on teaching mounted gymnastic balancing activities (i.e., vaulting) in order to enhance clients' confidence, organizational skills, spatial relations, body awareness, and sense of self-identity (Vidrine,Owen-Smith,Faulkner, 2002). Vidrine et al. found that as a result of therapeutic vaulting, adolescent clients' senses of self-awareness improved and clients reported feeling more accepted and valued. Ground 
activities (i.e., those that require no actual riding) can also be incorporated into EFP in order to facilitate client emotional development (Rothe et al., 2005). For example, activities like grooming horses and learning to properly saddle a horse have been found to increase clients' self-esteem (McDonald \& Cappo, 2003).

About two decades ago, several clinicians began to take note that clients spontaneously labeled or interpreted horses' behavior in ways that were analogous to the presenting problems that brought them into treatment (Heimlich, 2001; Kohanov, 2001; Levinson, 2006; McCormick \& McCormick, 1997). Essentially, Equine-assisted psychotherapy (EAP) evolved from the experiences of those utilizing horseback riding activities into a therapeutic modality that incorporates metaphors derived from client-horse interactions that are found to connect with the internal workings of people.

EAP is a natural evolutionary development with its roots in the experiential therapy movement of the 70's, when alternatives to traditional "talk" therapy were being developed (Zugich, Klontz, \& Leinart, 2005). EAP is achieving prominence as an effective therapeutic intervention (Kersten \& Thomas, 2004; Levinson, 2006; Rothe et al., 2005; Zugich et al., 2005).

One of the pioneers of EAP, Greg Kersten, combined his extensive equine knowledge and military background in his work with juvenile inmates in the 1980s. His therapeutic goals were achieved using ground-based rather than mounted activities. One of his legendary equine interventions involved about a dozen adjudicated youth with whom he was working (G. Kersten, personal communication June 20, 2003). Late in the day Kersten gave these clients the "simple" directive to round up all the horses in the paddock (about a dozen) and then come in for dinner. What these young clients discovered was that, as one horse was goaded into a corral, the other eleven bolted in all directions. It took hours of frustration but the youths eventually came upon a discovery: if they locked arms and formed their own "corral," they could maneuver the horses into a tighter herd and guide them through the corral gate. Kersten questioned the youth about "corrals" in their lives outside of the facility. The youths posited how they linked arms and worked as a united group to accomplish a mutual goal. This activity served as an apt metaphor for what they needed to do in their own lives to gain self-control and a sense of self-efficacy. It was through reports of such dramatic clinical successes that EAP became established as an intervention in its own right (Frewin \& Gardiner, 2005; Taylor, 2002).

In 1999, Kersten and Lynn Thomas, a licensed social worker, created the Equine Assisted Growth and Learning Association (EAGALA), a professional organization that publicizes EAP, offers support to counselors in the field, and administers the certification program, which is a series of training workshops with a three-tier process to provide systematic developmental procedures to increase skills utilizing EAP. More recently, Kersten has created another educational program called the O.K. Corral Educational Series, where O. K. stands for observation and knowledge. The O. K. program extends EAP principles to parents and teachers and helps them conceptualize how metaphors for change can be crafted without an actual horse being available.

EAP has grown into an experiential therapy that has attracted adherents throughout the Western Hemisphere, Europe, New Zealand, and Australia. Research has begun to support claims of juvenile recidivism rates. Mann's (2002) studies found that six of nine adjudicated juveniles were able to improve family relationships, decrease peer conflicts, pass drug evaluations, and increase school attendance following participation in EAP. Thomas (2002) studied youth in jail who received EAP treatment. After three months, $79 \%$ did not incur new offenses, as compared to the no treatment group (67\%).

Research indicates a decrease in mental illness symptoms among those receiving EAP (Rothe et al., 2005; Taylor, 2002). Studies by Kruger and Serpell (2006) posit that animals may serve as transitional objects to reducestress. Furst(2006) conducted anational survey of animal-assisted therapy within prisons. One 
finding indicates the need for male inmates to have an "acceptable outlet for touching and caressing” (p. 412), and provides a rationale for equine-assisted therapy in prisons. Studies have shown reductions in disciplinary actions, together with increased prisoner self-esteem and self-confidence, as a result of interaction with the equines.

The components of EAP provide a framework to discerning how this new experiential counseling may be responsible for a decrease in recidivism rates among juveniles and decreases in mental illness symptoms.

\section{Therapeutic Components}

EAP components include (a) a team approach toward treatment, (b) structured experiential problem-solving activities, and (c) a unique environmental setting.

\section{The Therapeutic Team}

The team approach breaks with traditional treatment in that it involves two human team members and at least one horse who each play a therapeutic role: a licensed mental health professional who oversees the course of treatment, an equine specialist who is an expert at handling horses, and, a horse whose actions are utilized by the counselor and client to generate metaphoric content. Horses are regarded as therapeutic team members, given their reactions to humans' internal feelings and uncovering "our own inner sense in bold, living, color” (McCormick \& McCormick, 1997, p. 6). The function of these unique "equine team members" will be further explained in this article.

Specifically, the licensed mental health professional serves to capitalize on the therapeutic potential of the horse and client interaction. To do this, the counselor attends to clients' verbal and nonverbal responses toward the horses, sees how those responses are parallel to the issues the clients bring to treatment, and links these into a co-created metaphor-or kind of working insight-for change. Equine specialists attend to the horse's reactive behaviors with the client. Counselors and equine specialists provide clients with emotional and physical safety, respectively.

EAP capitalizes on the unique fact that horses are at once both very social animals and fearful, skittish animals (Irwin \& Weber, 2001; Karol, 2007). Horses are constantly engaged in subtle communication amongst each other. One variant of their sociability is that the horses react to their environmental context: if one horse is frolicsome, there is a contagion effect such that the other horses in the herd tend to mimic that behavior. Horses are quick to respond to any threat by retreating
(Kersten \& Thomas, 1999). This fear can be triggered by something as simple as the breeze rustling someone's nylon jacket or a bird taking flight. Whether horses communicate by fleeing or fighting is a reflection of how they perceive the world around them. The horses' reactions (e.g., mimicking, retreating, aggressing, displaying curiosity) to clients become the grist for therapeutic processing and represent their contribution to the team.

\section{Problem-Solving Activities}

Structured experiential problem-solving activities are the essential mechanisms of what happens during EAP. Activities are designed to temporarily frustrate clients in order for them to have the opportunity to create or brainstorm solutions that are not immediately apparent. For example, clients might be instructed to catch and halter a horse, but such a seemingly simple task is made more challenging by the horses' natural skittishness or by the deviousness of the mental health professional who frustrates clients by mismatching the size of the halters. The challenge and the frustration create a situation whereby clients utilize problem-solving skills and engage in working cooperatively.

The actual activities evolve from the goals that are collaboratively crafted with and agreed upon by the client at the outset of EAP. The activities are intended to bring the client into an encounter with the horse that will generate self-exploration and insight into the issues that the client brings into treatment. The activities for helping a client develop problem-solving skills, for example, may be as basic as observing horses in the corral or catching and haltering a horse. A more challenging activity, such as constructing an obstacle course serves as an excellent paradigm for adjudicated youth to discuss what gets in their way of succeeding in the larger world outside of the paddock. Youths construct and label the "obstacles," agree upon the selection of a horse, and then guide the horse past the troublesome obstacles. Once accomplished, the processing that ensues leads to the therapy goal: discovering what this activity has to teach about making it down a life-path that is strewn with roadblocks.

\section{The Setting}

EAP's unique environmental setting conveys a dramatic message to clients who balk at traditional treatment. It says, "What we will be doing now in therapy will be different, creative, and compelling." Instead of a traditional counseling office that restricts physical movement and creates barriers (McCormick 
\& McCormick, 1997), an arena with the aroma of hay and containing a sleek, neighing horse may suggest opportunities for excitement, experimentation, and playfulness. The fact that the setting is so unique and operates by such unfamiliar rules means that, for adjudicated and many at-risk youngsters, their tendencies to move swiftly to defy treatment may momentarily be suspended which, in turn, may allow a window of therapeutic opportunity to open.

\section{Factors That May Account for EAP's Effectiveness}

Metaphoric communication is thought to be the primary mechanism responsible for facilitating change in EAP (Irwin \& Weber, 2001; Karol, 2007; Kersten \& Thomas, 1999). During EAP sessions, counselors often pose straightforward questions to clients that require a metaphorical response. For example, an introduction to an equine may begin with a question such as "What do you know so far about the horse you are observing right now? " Responses may be "I think he’s bossy and doesn’t like me because he moved away when I looked at him." Similarly, the counselor may present clients with the challenge of solving a structured task, such as moving a horse through an obstacle without touching the equine. A metaphoric solution forces clients to engage in representational thinking (Young \& Borders, 1998). Emerging from this process are new analogies for conceptualizing what constitutes a problem and the generating of newly discovered, general problemsolving principles that the counselor helps clients extrapolate into the world beyond the treatment setting. The EAP counselor uses the content and context of clients' responses to the-structured tasks to understand how clients-construe what the problem is and how it can be dealt with. Furthermore, this is deepened by the EAP counselor's attention to clients' language - the words and phrases clients emphasize or repeat as well as their descriptions of what they perceive is occurring. This, then, assists the counselor and equine specialist in constructing metaphors designed to help clients develop and retrieve emotional responses (Lyddon, Clay, \& Sparks, 2001).

The theoretical concept of metaphor is explicated by Korzybski, a renowned semantic theoretician-who coined the phrase "the map is not the territory" in 1933 (Sikes, 2006). This phrase refers to conceptually understanding that one's perception is not the reality itself but, rather, a version of it or a "map" (Sikes, 2006). Further implied in this "map" is the very need to understand another's communication about their world. From this stand point, metaphoric language is expounded as a language device (Kottler, 1994) that can represent how someone is experiencing their world.

Powerful insight is gained by "generating a wide variety of associations among previously unrelated cognitive structures" (Young \& Borders, 1998, p. 238). EAP metaphors are directed at four prime targets for facilitating behavioral/emotional changes. The first use of metaphors is to explain or account for the horse's puzzling behavior (e.g., what is the horse afraid of?). A second use of metaphor involves analogous language that references props used during activities with the horses (e.g., if the halter represents a way of controlling the horse, what device or tactic is used to control you?). The third involves the clients relating the life lessons they learned that were embedded within solving a structured task (e.g., what does it mean that all of you had to link arms in order to solve the problem of getting the horse over an obstacle?). The fourth, and probably the most clinically significant, is the way in which clients metaphorically extrapolate the lesson learned to coping more effectively with life's challenges (e.g., if teamwork is required to move the horse, then how do you "team" with others to solve issues beyond the horse arena?).

Characteristics of horses provide another mechanism thought responsible for EAP's effectiveness (Irwin \& Weber, 2001; Jarrell, 2005; Karol, 2007; McCormick \& McCormick, 1997). Equines appear to have the uncanny ability to resonate in a complementary fashion with the emotions emanating from humans. Karol posits that a horse's sensitivity and reactiveness, which provides unambiguous, immediate feedback to the client, can model how the individual is behaving. For example, if clients are angry, horses instinctively perceive and mirror that anger through such patterns as pinning their ears back or aggressively chasing another horse. Another characteristic of horses is that they seem to accept people (even clients) without judging or labeling anyone as "troubled" or "resistive" (Fawsett \& Gullone, n.d.; Kersten \& Thomas, 1999). In other words, horses appear to provide a milieu for emotional growth (McCormick \& McCormick). 


\section{Implementation of EAP: Getting Started}

EAP has been utilized with individual clients ranging in ages from 4 to over 80 (Karol, 2007; Taylor, 2001), and with couples, families, and groups. One application of EAP is in the realm of improving clients' communication and increasing social skills. For example, business corporations have turned to EAP to enhance teambuilding among employees (Rothe et. al. 2005). Clients with presenting problems such as Asperger's syndrome and attention deficit disorder seem to increase their problem-solving skills and perceptiveness of nonverbal cues in relationships (McCormick \& McCormick, 1997; Magnelli, Magnelli \& Howard, 2006; Traumutt, 2003; Tyler, 1994). Another, more clinically oriented application of EAP, has yielded positive results with clients diagnosed with

depression, anxiety, posttraumatic stress disorders, and adjustment disorders, to name only several (Rothe et.al. 2005; Taylor, 2002). Tetreault (2006) and Trotter's (2006) studies show improvements in oppositional behaviors and social interactions for youth involved in EAP.

In this article we focus more on the descriptions of launching a clinical application of EAP. With most clinical applications of EAP, a first consideration is time allotted for the therapy. Typically counselors meet with individuals, couples, families, and groups for 8-12 sessions. Individual and couple sessions are 50-60 minutes in duration, whereas families and groups meet for 90 minutes. A second consideration, and one of the most important for the clinical application of EAP, is the selection of the horse(s) for an anticipated activity. Even before the client(s) enters the arena for a session, the horses are specifically chosen based on what is known about the client's presenting problem(s) and the horse's likelihood of responding to initial behaviors.

An example can illustrate the dynamics involved in matching horses with clients. The first author of this article was recently working with a group of six juvenile boys and gave them the task of selecting one horse from a herd of three. The juveniles chose the smallest one and when asked their reason why, they explained that her diminutive stature and stationary posture, in their perceptions, made her "the easiest one to control." The next session revealed that the horse was anything but controllable and moved away from the boys' attempts to approach her. With the third session, this horse was removed and a new horse from the herd was introduced. Incidentally, the boys learned the valuable lesson that size does not predict whether horses (or people) will knuckle under.

Structured activities begin with observing herd dynamics and noting client descriptions of relational interactions within the herd. Verbal and nonverbal responses may reveal the emotional inner-workings of clients. Included in this introductory session is asking clients how horses communicate. A discussion of safety rules when interacting with the horses leads to observations of tails switching, ear movements, and feet-stomping. Clients are then given a physical task, such as choosing and getting to know each horse by brushing them. Noting what tool they choose, which horse they approach and how they approach the horse, all provide a myriad of information for metaphorical redefinitions and re-storying.

Sessions culminate with a dialogue between the therapy team and clients around questions raised as a 
result of the observed interactions between client and horse. An example of a dialogue is the following:

Counselor: How did you choose which horse to brush?

Client: I chose the little one because it wouldn't run away from me.

Counselor: What would it mean if the horse would run away?

Client: It means he didn't trust me.

Counselor: You mean you want a horse that you can trust will stick by you?

Client: Sure, 'cause there's no sense messin' with a horse that doesn't like me.

Counselor: How does that apply to people you've known?

The last agenda item of a session is assigning therapeutic homework based on what occurred during the session. For example, the client in the above dialogue might be given homework to write about how trust is demonstrated in family and peer relationships. The six clients referred to earlier were to write about what else they learned about the horses and themselves regarding "control."

Each subsequent session begins with a review of what transpired during the previous session and discussion of homework. Next, the client is asked to gauge the emotional reactivity level of the horse he or she is to work with today. Thus, the client might be asked, "Jose, how do you think the horses are feeling today?" and Jose might respond, "They don't want to be bothered. I think they're angry at something.” This is called a "check-in" and is crucial because it may be a metaphorical representation of how the client is feeling at the beginning of the session and may provide valuable clues about what might transpire later in the session. After the check-in, clients are presented with one representative problem-solving activity. The activity can range widely from catching and haltering the horse to constructing a series of complicated obstacles to move the horse through. It is important to note that the goal of each session is not to "complete" an activity; rather it is to understand how problem-solving is occurring. Many sessions may be repeated with the same activity until clients respond that the goal has been achieved to their satisfaction. One of the by-products of EAP is that clients may learn to trust their internal locus of control and decision-making capabilities.

\section{Discussion}

EAP presented in this paper explicated the origins of EAP and the process of implementation. Primary change mechanisms and metaphoric application, further described how this therapeutic treatment is crafted and utilized during counseling.

There are some limitations with an EAP approach. One of these is the cost. Insurance coverage has not been a detour to EAP, however fees in addition to the counselor need to include the equine-specialist and arena cost for an hour session. These generally are $\$ 50.00$.

The majority of counselors have little to no training with equines (nor do the clients) and thus the partnering with an equine specialist is mandatory for safety. Additionally, some counselors are not comfortable with equines. Allergies for counselors and clients may also be a deterrent. While EAP trainings for both counselors and equine specialists have increased, the educational seminars are three full days. Gaining knowledge in EAP is a continuous on-going endeavor.

Issues with an arena can be limitations. The weather also may be plagued with frigid or sweltering temperatures. Thus, sessions may be cancelled and create difficulty for consistency. The availability of an arena that provides strict confidentiality may present difficulties.

Even with limitations, EAP may still be a therapeutic method to provide the "arena" for youth to create new choices and durable behavioral changes. Research, both qualitative and quantitative, is needed to further explicate the power of equines for treatment. In the meantime, it bears attention to look at new creative means to accomplish therapeutic goals for difficult youth. 


\section{References}

Clark, M. D. (2001). Influencing positive behavior change: Increasing the therapeutic approach of juvenile courts. Federal Probation, 65, 18-27.

De Gutis, D.L. (2003). Hippotherapy aids children with sensory and motor issues. Exceptional Child, 33, 55-57, 59.

Fawsett, N. R. \& Gullone, E. (n.d.) Preventive intervention for conduct disorder: Consideration of a novel approach involving animal-assisted therapy. Department of Psychology, Monash University, Monash Victoria, Australia.

Frewin, K. \& Gardiner, B. (2005). New age or old sage? A review of equine assisted psychotherapy. Journal of Counseling Psychology, 6, 13-17.

Furst, G. (2006). Prison-based animal programs: A national survey. The Prison Journal, 86, 407-430.

Glasow, B. L. (2006). Semantics-to be exuberant or to be correct. American Hippotherapy Association. Retrieved August 15, 2006 from http:///www.americanhippotherapyasscoaition.org/aha_hpot_A-semantics.htm

Hanna, F .J., Hanna, C. A., \& Keys, S. G. (1999). Fifty strategies for counseling defiant, aggressive adolescents: Reaching, accepting, and relating. Journal of Counseling \& Development, 77, 395-404.

Heimlich, K. (2001). Animal-assisted therapy and the severely disabled child: A quantitative study. Journal of Rehabilitation, 67, 48-54.

Irwin, C. \& Weber, B. (2001). Horses don’t lie: What horses teach us about our natural capacity for awareness, confidence, courage, and trust. New York: Marlowe.

Jarrell, N. (2005). Equine therapy: Making the connection. Counselor The Magazine for Addiction Professionals. Retrieved September 15, 2006 from http://www.counselormagazine.com/content/view/72/63/

Karol, J. (2007). Applying a traditional individual psychotherapy model to equine-facilitated psychotherapy (EFP): Theory and method. Clinical Child Psychology and Psychiatry, 12, 77-89.

Kersten, G. \& Thomas, L. (1999). Equine assisted psychotherapy and learning training manual level I. Santaquin, UT: EAGALA, Inc.

Kersten, G. \& Thomas, L. (2004). Equine assisted psychotherapy and learning. Un-training manual level II. Santaquin, UT: EAGALA, Inc.

Kohanov, L. (2001). Tao of equus. Novato, CA: New World Library.

Kottler, J. A. (1994). Advanced group leadership. Belmont, CA: Brooks/Cole Publishing.

Kruger, K. A. \& Serpell, J. (2006). Animal-assisted interventions in mental health: Definitions and theoretical foundations. In Kruger \& Serpell (Eds.), Handbook on Animal-Assisted Therapy (2nd ed), (pp.21-38).

Kruger, K. A., Trachtenberg, S. W., \& Serpell, J. (2004). Can animals help humans heal? Animal-assisted interventions in adolescent mental health. Symposium at the Center for the Intervention of Animals and Society ( pp. 1-37). University of Pennsylvania Press.

Levinson, F. (2006). Equine facilitated learning. Frank Levinson’s World of Equestrian Adventures \& Horsemanship. Retrieved July 18, 2006 from http://www.wayof thehorse.org/Artciles/equine-fac-learning.html

Lyddon, W. J., Clay, A. L., \& Sparks, C. L. (2001). Metaphor and change in counseling. Journal of Counseling and Development, 79, 269-274. 


\section{References}

Magnelli, R. G., Magnelli, N., \& Howard, V. (2006). The efficacy of an equine-assisted psychotherapy program with atrisk youth: EAGALA. Retrieved September 28, 2007 from www.eagala.org.

Mann, D. S. (2002). Equine-assisted family therapy for high-risk youth: Defining a model of treatment and measuring effectiveness. Retrieved September 28, 2007 from http://www.eagal.org.

McCormick, A. \& McCormick, A. (1997). Horse sense and the human heart. Deerfield Beach, FL: Health Communications, Inc.

McDonald, P. M., \& Cappo, J. (2003). Equine facilitated mental health with at-risk youth. Does it work? NAHRA Strides, 30-31.

Morrison, M. L. (2007). Health benefits of animal-assisted interventions. Complementary Health Practice Review, 12, 5162.

Parshall, D. P. (2003). Research and reflection: Animal-assisted therapy in mental health settings. Counseling and Values, 48, 47-56.

Pitts, J. L. (2005). Why animal assisted therapy is important for children and youth. Exceptional Parent, 35, 38-39.

Rothe, E. Q., Vega, B. J., Torres, R. M., Soler, S. M. C., \& Pazos, R. M. M. (2005). From kids and horses: Equine facilitated psychotherapy for children. International Journal of Clinical Psychology, 5, 373-383.

Sharkey, J. D., Furlong, M. J., Jimerson, S. R., \& O’Brien, K. M. (2003). Evaluating the utility of a risk assessment predict recidivism among male and female adolescents. Education and Treatment of Children, 26, 467-494.

Sikes, R. S. (2006). The map is not the territory. Idea Seminars. Retrieved 10/22/06 from http://www.idea-seminars.com/ articles/map.html.

Taylor, S. M. (2002) Equine facilitated psychotherapy. An emerging field. Paper submitted in Clinical Psychology of Saint Michael's College impartial fulfillment for a degree of Master of Arts. Colchester, VT.

Tetreault, A. (2006). Horses that heal: The effectiveness of equine assisted growth and learning on the behavior of students diagnosed with emotional disorder. Unpublished manuscript, Governors Sate University, University Park, Illinois.

Thomas, L. (2002). Horse-play can be therapeutic: Equine assisted psychotherapy. Woodbury Reports, 100, 10-11.

Traumutt, J. (2003). Opening the gate: Cultivating self awareness and self acceptance through equine-assisted psychotherapy. Unpublished masters’ thesis, Naropa University, Boulder, Colorado.

Trotter, K. S. (2006). The efficacy of equine assisted group counseling with at-risk children and adolescents. Paper presented at the American Counseling Association National Conference, Kansas City, Missouri.

Tyler, J. J. (1994). Equine psychotherapy: Worth more than just a horse laugh. Women and Therapy, 15, 139-146.

Vidrine, M., Owen-Smith, P., \& Faulkner, P. (2002). Equine-facilitated group psychotherapy: applications for therapeutic vaulting. Issues in Mental Health Nursing, 23, 587-603.

Young, J. S., \& Borders, D. L. (1998). The impact of metaphor on clinical hypothesis formation and perceived supervisor characteristics. Counselor Education and Supervision, 37, 238-256.

Zugich, M., Klontz, T., \& Leinart, D. The miracles of equine therapy. Counselor Magazine, Descember. Retrieved May 2, 2005 from the World Wide Web: http://www.counselor magazine.com/pfv.asp?aid=The\%20Miracle\%20DECEMBER.htm 